\title{
EFFECTS OF POSTERIOR ROOT SECTION ON THE ACTIVITY OF SOME MUSCLES IN MAN
}

\author{
BY \\ P. W. NATHAN and T. A. SEARS \\ From the Neurological Research Unit of the Medical Research Council and the Institute \\ of Neurology, National Hospital for Nervous Diseases, Queen Square, London
}

Occasionally the opportunity occurs of examining the activity of muscles in man before and after cutting the posterior roots. Before recording our findings in three patients, we review and discuss the observations of previous workers who have studied the effects of cutting the posterior roots on movements in the monkey, cat, dog, and man.

\section{Previous Observations}

Effects of Cutting Posterior Roots on Limb Movements.-In 1811, Charles Bell presented evidence "that the nerves of sense and the nerves of motion are distinct through their whole course, though they seem sometimes united in one bundle"; he established that the anterior roots are motor, and he "offered reasons for believing" that the posterior roots are sensory. After Sir Charles Bell's idea was accepted, one of the next questions to ask was what effect cutting the posterior roots might have on motor activities.

Monkeys.-Mott and Sherrington (1895) studied this problem by dividing the posterior roots from the forelimb or hindlimb in the monkey. They kept these animals under observation "up to and over three months", and they confirmed histologically that the roots had been cut. They wrote:

"From the time of performance of the section onwards, the movements of the hand and foot are practically abolished; the movement of grasping, which is so useful to the monkey, both with the hand and foot, never occurs at all in our experience. On the other hand, the movements at the elbow and knee, and especially the movements at the shoulder and hip, are much less impaired."

As the animals ran about they did not use the deafferented hindlimb. The deafferented limbs were used, however, when the animals were made to struggle or were frightened. Mott and Sherrington were

"led to conclude that associated movements in the limb ("Mitbewegungen") are comparatively little impaired by loss of the sensation from the limb in which they occur; but that the independent and more delicately adjusted movements which employ preponderantly the smaller and more individual muscular masses of the hand and foot, and serve to move the digits, especially the hallux and thumb, are extremely severely impaired, and, in some instances, are abolished."

Mott and Sherrington then investigated the effects of such unilateral deafferentation on movements produced by electrically stimulating the cortex and by giving absinthe intravenously. With electrical stimulation they found no difference in the movements of the limbs of the two sides; and with the bilateral convulsions induced by the absinthe theyo found that "convulsions sometimes started in the normal and desensitised limb simultaneously, sometimes a little earlier in one or the other". Sherrington wrote of this in 1931:

"When the motor cortex is examined by electrical stimulation, not only does it evoke in the deafferented arm and hand the customary movements just as readilyô. as usual, but these movements reveal no obvious? departure from their usual coordination."

However, it seems that these deafferented limbs were not always as little used in "voluntary" activity as would appear from this evidence. In 1897, Hering published some further observations that Mott and Sherrington had sent him; they had observed one young monkey using its deafferented upper limb an hour and a half after division of the posterior roots. In using the limb, "the hand showed choreiform movements in trying to seize a piece of food." Hering has also left us more detailed accounts on the effects of this operation on Sherrington's monkeys, for he went to Liverpool to study the effects of deafferentation on the movements of a limb. He reported that a monkey, in which Sherrington had divided the posterior roots from an upper limb, when it climbed would move the limb "upwards and backwards, so that the extremity moved in an aimless manner in the air up above and behind the head"; this kind of movement also occurred when the animal tried to scratch its back with its deafferented hand. The impression obtained from Hering's account of Sherrington's 
monkeys is different from that given by Mott and Sherrington's; Hering's account is certainly not that of a monkey which does not attempt to use the limb.

The most detailed account of the effects of deafferentation in the monkey is that of Munk. He first reported his observations to the Berlin Academy of Sciences in 1903, later publishing them in his book "Functions of the Brain and Spinal Cord" in 1909. Munk saw, as Mott and Sherrington had done, that immediately after the operation the monkey did not use its hand. But after having its normally innervated upper limb bound behind its back, the animal learned to use the deafferented hand to convey food to its mouth, and to open and close the hand, moving the fingers and thumbs separately. If the monkey saw Munk trying to seize hold of its deafferented limb or threaten it with a stick, it moved the limb behind its back. His animals learned to grip, to shut their fingers round a piece of carrot, to take a carrot from between the bars of the cage and bring it to their mouths. "In short, all movements that can be performed by an upper limb eventually appeared." In his later experiments Munk found that it was unnecessary to keep binding the normally innervated limb, for if the monkey was prevented from using it on only a few occasions soon after the operation, it would learn to use the deafferented limb. He further reported that some animals were able to use the whole limb as soon as the effects of the general anaesthetic had worn off.

Munk therefore came to the conclusion-unlike Mott and Sherrington-that use of a limb can be achieved without afferent impulses from the limb. $\mathrm{He}$ further concluded that those movements of a limb made in conjunction with the other limbswhich he called "Gemeinschaftbewegungen"-are severely impaired. Munk agreed with Mott and Sherrington in his observations that during normal running around and climbing the monkey did not use the deafferented limb; and he also agreed with them in his observations that the animals, under the influence of fear, or when running or climbing rapidly and excitedly, would sometimes make the appropriate movements of the deafferented limb in association with the other limbs, though such movements were inadequate. Munk was particularly struck how improvement never occurred in the "Gemeinschaftbewegungen", in contrast to the improvement that occurred when the limb was used alone, as in taking a piece of food. On such occasions, the animal used its deafferented hand and digits. This was never seen by Mott and Sherrington. Munk therefore concluded that there is no "lack of will" to use the limb and that the engram (Vorstellung) of movements is not lost. That is not to say that movements are carried out normally; they are ataxic, dysmetric, and are performed clumsily; indeed he states, "All movements of the extremity are damaged"; but they are not, as Mott and Sherrington had stated, "practically abolished". $\mathrm{He}$ concluded that "Gemeinschaftbewegungen" are permanently disturbed by deafferentation, and that associated movements also suffer considerably; and he contrasted this with the relatively good functioning of the limb when it was used on its own in purposive movements. Mott and Sherrington considered that the relatively good performance of associated movements, particularly of the shoulder, stood out in contrast to the great diminution in purposive movements. It may be that both groups of workers saw the same kind of associated movements; Munk contrasted these with the excellent purposive movements of his monkeys; Mott and Sherrington contrasted them with the almost complete lack of purposive movements of theirs. It may also be that various workers used the term "associated movements" to mean different things.

Lassek (1953a and b, 1955) and Lassek and Moyer (1956) reported observations on the effects of posterior rhizotomy; the cutting of the roots was confirmed histologically. In all, 36 adult monkeys and one monkey aged 4 weeks were mentioned, but it is not clear how many of these monkeys appeared in more than one paper of the series; in 16 of the adult monkeys other lesions as well as the posterior rhizotomies were made. These results accord entirely with those of Mott and Sherrington. Lassek found the operation causes

\begin{abstract}
"an almost complete paralysis, only the crudest possible motion being retained. This latter consists of rare random and aimless movements generated at the shoulder joint. Stimuli of emotional origin are capable of breaking through the lower motor neurones only on violent struggling."
\end{abstract}

The deafferented limb was not used "in supporting the body weight in the sitting position, for progress, for grasping the wire meshes of the cages, for climbing or for eating." He observed "little or no signs of restitution of function." In his report on posterior rhizotomies combined with other lesions (1955), he stated that the animals with posterior rhizotomies have more serious deficits than those with removal of the parietal cortex; and recovery from the cortical lesion is more rapid and more complete. In the infant monkey with a deafferented upper limb, Lassek and Moyer (1956) never saw individual finger movements throughout the eight months of the animal's life; this limb performed "random and aimless movements with clenching of the fist"; but the monkey could eventually reach for "and partially grasp the meshed wires". 
Twitchell (1954) reported his observations after deafferenting one upper limb in monkeys. He found this caused a severe motor deficit, which "amounted to a virtual paralysis of the limb". The monkey never again used the hand for grasping. But "from two to six days after the operation the monkey defended himself by flexing the arm, catching the offending object with the wrist or forearm, and pulling or scraping it to his mouth". Twitchell also observed movements of the deafferented limb associated with climbing, particularly when the animal was excited. Twitchell considered that the animal learned to compensate for its loss of sensory input by using its eyes. He believed that when the animal used its limb, it did so by adapting the flexion and extension of the neck reflexes to form purposive movements. After division of all the more cranial posterior roots bilaterally, both the neck reflexes and these purposive movements disappeared. Although Twitchell's work provides evidence that the movements he observed were dependent on the neck reflexes, this mechanism cannot account entirely for the complicated purposive movements described by Munk in the ape and by Förster in man.

From reading the observations and deductions of those who have studied the effects of deafferentation on the limbs of the monkey, one sees that the views are conflicting. Not only did the monkeys of the various workers show different features, but often they were of opposite character; and, more disturbing, the very monkeys observed by one worker apparently showed different behaviour when observed by another. Mott and Sherrington, Lassek, and Twitchell claimed that the monkey is almost paralysed, whereas Munk and Hering claimed that it is far from paralysed and can perform many tasks with the deafferented limb and hand. Although Mott and Sherrington stated that the movements of the hand were practically abolished by deafferentation and that the "movement of grasping never once occurs in all our experience", Sherrington wrote to Hering that one monkey showed movements of the deafferented limb one and a half hours after the operation, and that the movements consisted of an attempt to use the hand to take food. In Hering's account of the monkeys deafferented by Sherrington, it was reported that when the animal tried to scratch its back with its deafferented hand, the movements were very badly coordinated. But from reading Mott and Sherrington's account the impression is gained that the animal could not use the deafferented limb to carry out such movements. The observations of Lassek and Moyer are similar to those published by Mott and Sherrington. Twitchell also reported similar observations, although his monkey did not show so complete a paralysis: it defended itself by flexing the arm and it would try to catch the object with which it was being menaced, pulling or scraping it to its mouth. Munk claimed that deafferentation does not permanently and completely remove useful movements of a limb. His detailed account of the exact performance of various movements carried out by his monkeys, in which he describes how they placed their thumbs and fingers so as to move a piece of carrot from between the bars of the cage and how they brought the food to their mouths and other similar activities, is very convincing. Unfortunately Munk's work has remained unheeded; we have found no reference to it by any of the workers in this field; and Sherrington made no mention of it in his later comments on the effects of deafferentation, published in 1931.

One has to account for the different post-operative behaviour observed by the various workers. An important difference seems to be the extent to which the animals were forced to use the deafferented limb by being prevented from using the normal limbs. Lassek and Twitchell did not bind the normally innervated limbs of their monkeys; Mott and Sherrington did this to some extent; Munk did so routinely. Munk seems to have trained his animals to use the deafferented limb. The fact that he repeatedly gave his monkeys tasks to do with the deafferented limb while preventing them using the other limb and rewarded them when they succeeded in using the limb for performing these tasks, constitutes an effective form of training. It may be that this difference in post-operative training is responsible for the different observations made by the different workers. But this explanation cannot account for all the differences observed in the behaviour of the monkeys; for Munk saw his animals moving the deafferented limb away from the trunk when they needed to scratch themselves in a part covered by the limb, and he saw them sitting in their cages performing all movements of the limb, including pronation and supination of the hand, extending, flexing, and spreading out the fingers. It seems then that the definite statements of Mott and Sherrington and of Lassek that animals cannot use their fingers and hands after deafferentation of the limb requires modification. For Munk paid particular attention to the use of the fingers and hand and insists that monkeys re-learn these movements.

There is agreement by all observers that increased emotional motivation, such as fear, enables the monkey to perform movements that it otherwise does not do. It is also agreed that movements needing an orderly cooperation of the deafferented 
limb with the other limb or limbs are seriously disturbed, and that little or no improvement occurs.

In 1895, Bastian also observed Mott and Sherrington's monkeys, and reported his conclusions about the inactivity of the deafferented limbs to the Royal Society as follows:

"We have here a lowered functional activity in the motor centres themselves situated in the spinal cord by reason of which their molecular activity is so altered that they are no longer capable of responding to ordinary volitional stimuli coming from the cerebral cortex. . . The immediate result of this may be presumed to be a lowering of the habitual sub-activity of the motor centres upon which the condition of tonus in the muscles depends. . . Muscles may not respond to ordinary volitional stimuli, and yet may respond when the stimulus is strengthened under the influence of emotion. In a similar manner may we explain the fact that when . . . the centres are stimulated by electricity, movements of the previously paralysed limbs are produced just as easily as they are in a normal limb.'

This statement seems to us to accord with much experimental work on the "molecular activity of the spinal cord motor centres" done in recent years.

Dog.-In 1897, von Korniloff demonstrated dogs in which he had deafferented one hindlimb to the International Medical Congress in Moscow, publishing the results in 1898; the posterior rhizotomies were confirmed at necropsy a few months later. His results will not be given here as they are similar to those of Bickel, which will be considered in greater detail. Bickel (1897) reported many experiments on young dogs, in which he deafferented one or both hindlimbs. In the book on the subject which he published in 1903 (which is mentioned by no worker except Sherrington), he reported further experiments: these consisted of deafferenting the hindlimbs and removing the sensori-motor cortex for all four limbs; in one group the first of the two operations was the deafferentation and in the other group the removal of the cortex was done first.

Bickel considered that the post-operative period is best regarded as consisting of three stages: "a pseudo-paralysis stage, a stage of severe ataxia, and a stage of compensation for this ataxia." In the stage of pseudoparalysis, although the deafferented limbs do not support the body, the abdomen and posterior limbs being merely dragged along the ground, the limbs are not in fact paralysed; they can perform energetic but inefficient movements; when these animals are held up by the scruff of the neck, all four limbs make running movements. Gradually these dogs learn to stand, walk, run, and eventually to use the deafferented hindlimbs for scratching; they could even stand on their hindlimbs, and they learnt to go up and down stairs; they could jump down from a chair and even jump over a fence without catching their hindpaws. But the movements of these limbs were "completely unregulated". Bickel describes how when these dogs run, the deafferented legs go all over the place "as if it was important to the dog only to move them, the purpose of the movements being of no interest". Eventually, however, compensation is so complete that,

\begin{abstract}
"It is really remarkable how slight the disturbances are when one thinks of the nature of the lesion which the dog has suffered. . . . When the dog plays at fighting with the other dogs in the courtyard, plays around in the grass, jumps up, running away from its pursuers, stands on its hindlegs to look up into a tree, or wildly rushes after a piece of meat amongst its comrades, then an unpractised eye can hardly tell this dog from its normal companions."
\end{abstract}

Not all animals, however, attain this degree of compensation, there being differences between the various dogs, according to the character and the temperament of the individual animal.

Bickel found that all disorders were less after deafferentation of both hindlimbs than after one. For instance, running was always more abnormal in these dogs; when they ran they might take some steps more or less normally, then the deafferented limb might "be left in inactivity" for a step or two. But in the dogs with both hindlimbs deafferented running was almost normal.

Man.-Förster (1911) reported the observations he made in man following severance of the posterior roots, an operation that he introduced as treatment for spasticity; and in 1913 he published a further account of his experience. From his reports it is clear that in man the lower limbs can be voluntarily moved after posterior roots have been cut, although it is not clear if the limbs in these cases were ever completely deafferented. In his Handbuch (1936), Förster again wrote about the effects of deafferentation on movements in man. The value of this account for answering the question of what effects deafferentation has on the activity of a limb and of its muscles is somewhat less than might have been hoped; for observations and interpretations are inextricably mingled and it is, moreover, dificult to sort out when Förster is discussing tabes dorsalis and when he is referring to patients with proved division of posterior roots. Nevertheless, from these three accounts certain definite facts concerning the effects of cutting the posterior roots in man on the ability to use the limb can be gathered.

It is clear that immediately after operation man can perform simple movements with the deafferented limb, yet these movements are defective. For example, the forearm may be moved when it should be kept still, or a movement may suddenly stop in 
the middle of its course; extension may replace flexion and vice versa. All movements, particularly those of the prime movers, are excessive in range; the antagonists may fail to contract reciprocally.

"When the patient is required to bring his hand to his mouth, he hits himself in the face, and when he has to take hold of something in his fingers, he grips it with such vehemence that he may break or crush the object."

Förster writes that often when the patient tries to avoid exaggerated activity of the prime movers, he uses the antagonists from the beginning

"so that the movement is unnecessarily braked, and in fact the use of the antagonists may be so excessive that actually the opposite movement to that intended is eventually carried out."

Thus attempts at correction fail because the corrective movements are themselves accompanied by gross exaggerations in amplitude and strength. In addition to the general incoordination, all movements are often interrupted by "useless associated movements (Mitbewegungen)".

Altenburger (1937) has also reported his observations on the effects of dividing the posterior roots in man; his material included, if it did not entirely consist of, the patients operated upon by Förster and Guttmann. His account is largely the same as that of Förster, although, unlike him, he stresses that the synergists take part in movements in the normal manner and order, without the aid of visual control. Altenburger has provided some excellent electromyograms from these deafferented muscles; he first presented these in 1928, later publishing them in more detail in the Handbuch (1937). He examined muscles electromyographically before, half an hour after, and 16 days after division of their posterior roots. After deafferentation he found a great increase in the "amplitude and the rate" of the E.M.G. He showed that when a deafferented upper limb is required to be held out against gravity or to support a weight, the action potentials of the deltoid muscle increase in frequency and amplitude, just as in the normal. In general, he found that antagonists still relaxed reciprocally and that the temporal relation of the movements of the synergists to the antagonists was normal. He showed too that the typical exaggeration of movements that followed cutting the posterior roots is not due to a failure of contraction of the antagonists. It is thus seen that Altenburger and Förster presented different accounts of what occurs following deafferentation in man.

Before summarizing what is known about the effects of cutting the posterior roots on the movements of a limb, it should be mentioned that those who have performed this operation on monkeys have made different and often incompatible observations, and that the reports on the dog come mainly from one worker. The observations on man are few, and they do not include accounts of subjective observations by the patients; such information is likely to be illuminating in a condition with such deprivation of sensory information. It has been found, as would have been expected, that individual dogs and monkeys differ one from another; and also that there are differences according to the different species.

Cutting the posterior roots does not paralyse the limbs, although such a description has been given of the state soon after the operation. Although deafferented limbs can be used, all movements are abnormal, being badly coordinated and ataxic; the intended movements are interrupted by unnecessary and excessive movements, and the integration of contraction and relaxation of the limb muscles and of the limb in the total organization of the whole body is much disturbed. Individuals of all species investigated were found to be able to compensate to some extent for these deficits. The degree to which an animal uses the deafferented limb seems to depend partly on post-operative training. The dog and the monkey are able to carry out all activities with the deafferented limb that they could $\stackrel{\mathrm{\Phi}}{\mathrm{D}}$ do before. All this behaviour, even standing and $\propto \overrightarrow{2}$ walking in the dog with both hindlimbs deafferented, 응 has to be re-learnt. Yet this animal can do this so well that it has been said that only a practised eye can tell the dog with deafferented hindlimbs from its normal companions, when it is living in the pack, and not subjected to special tests requiring careful coordination of the limbs. Before the animal has re-learnt, motivation plays an important part in the animal's use of the limb: when a strong emotion, such as fear or hunger, drives the animal, movements are seen in the deafferented limb that are not present at other times. In the dog more disability results from deafferenting one hindlimb than from deafferenting both; such double deafferentation has not been performed in monkey or man. In the monkey it is probable that neck reflexes are used to help the movements of the deafferented upper limb. Although deafferented limbs are used for purposive movements, they are not used in a normal way, for without afferent surveillance, all movements are clumsy; they may overshoot or fall short of the mark. All the abnormalities are more marked for the hand and digits than for the forearm and arm in monkey, and probably in man.

Effects of Cutting Posterior Roots on Limb Posture and Tone.-It is usually believed that deafferented limbs are toneless and devoid of 
posture; tone, being dependent on the integrity of proprioceptive reflexes from the limb, might be expected to be absent in a deafferented limb. The observations of those who have studied the effects of posterior rhizotomy lend little support to this belief.

Monkeys.-Mott and Sherrington (1895) reported that tone in their monkeys was much diminished. Yet their account relating that "the forelimb swings helplessly, with flexion at elbow and wrist and adduction at shoulder, in much the same position as if carried in a sling", and that the hindlimb when the animal was climbing was "kept more or less flexed at the hip or knee" seems to show that some tone must have been present; moreover, it had a particular distribution, leading to flexion and adduction in the forelimb and flexion in the hindlimb. The flexion at the elbow can be clearly seen from the photographs published by Sherrington in 1931. Although Mott and Sherrington described this posture, its presence was apparently never commented upon by Sherrington as providing evidence for the existence of tone in a deafferented limb. The reason for this may be that when Mott and Sherrington first published the work on deafferentation (1895) they were not concerned with tone. Sherrington worked on decerebrate rigidity in dogs and cats in 1896, publishing his account of it in 1898; by this time he had shown that a limb showing the sustained contraction of decerebrate rigidity "at once falls into flaccidity" when its posterior roots are cut, and that if the roots are cut before decerebration, the rigidity does not develop. The fact, then, that in deafferented limbs there is ever any kind of tone is surprising.

Munk $(1903,1909)$ reported that when his monkeys were sitting, "the anaesthetic limb hung down loosely, the forearm and fingers slightly flexed; when the animal walked or climbed, the limb remained in the same position." The limb is, he writes, "as flaccid as the limb of a corpse."

Lassek (1953b, 1955) found in his monkeys that cutting the posterior roots of the brachial plexus causes flaccidity: "little or no tone can be detected." This state continued for four months, the longest period of observation of the adult monkeys. However, in the paper with Moyer (1956) he described in a monkey with a deafferented forelimb that the tone was generally decreased, "but the tone in the flexor muscles of the fingers always exceeds that in the extensors so that the distal muscles remain in an almost constant state of flexion." Of particular importance is the report of Twitchell (1954). He observed regarding the deafferented forelimb that: "When the animal walked or ran, the affected limb was slightly flexed at the shoulder, and elbow, so that the hand did not touch the ground". In these animals he "abolished the neck reflex by sectioning the posterior roots of the most cranial cervical segments bilaterally"; he then found that "the affected limb hung completely flaccid;" and that movements of the head no longer induced changes in the posture of the limb.

Cat and Dog.--von Korniloff (1898) found that following deafferentation of the dog's hindlimb strong tonic extension of the limb developed; when the limb was forcibly flexed, it returned on being released to its previous position of extension. This extensor posture continued for four months, the longest period the dogs were kept alive after the operation. On the other hand, Bickel (1903) described the deafferented hindlimbs of his dogs as flaccid; the knees were flexed and the leg and foot were dragged along, dorsal surface to the ground; but eventually some tone, both extensor and flexor, was regained, so that the hindlimbs were able to support the weight of the body. Bickel pointed out that limbs with the corresponding sensorimotor cortical area excised are spastic, those with the posterior roots cut are flaccid, and those with both posterior roots cut and sensorimotor cortex excised are spastic; this shows clearly that deafferented limbs may possess tone.

Ranson (1928) was particularly interested in the effects of deafferentation on "tone" and posture, for he realised that Mott and Sherrington's account of the posture of their animals was discrepant with Sherrington's work, demonstrating that "tone" depended on the integrity of the posterior roots. When Ranson deafferented the hindlimb of cats, he found that "as soon as the cat recovers from the anaesthetic, the anaesthetic leg is flaccid, and, although it is not entirely paralysed, its movements are more limited than those of the normal leg. . . . Within 48 hours, however, a pronounced change in the condition of the limb usually occurs. An overaction of the deafferented extensor muscles develops, which may or may not be accompanied by an increased resistance to passive flexion." There was also adduction, which interfered with standing, the animals often falling over on to the deafferented limb; they could not prevent this by flexing and abducting the limb. This condition lasted two to four weeks. As the extensor tone then diminished, the animals began to walk again. The difficulty they had in walking appeared to be due to the failure to relax of the extensors, which stopped the flexors bringing the leg forwards. Though walking improved, the animals still had difficulty in flexing the limb, which "tended to be dragged with the dorsal side of the foot down." In a minority of the cats, this overactivity of the extensors did not 
develop. These cats showed weakness and ataxia of the limb, which tended to bend under their weight.

Lassek and Moyer (1956) found that deafferenting the forelimb of a kitten caused "the affected limb to hang straight down with the elbow in extension and the wrist in flexion. It can be used for a slight amount of postural support in this state with some weight exerted on the dorsum of the wrist."

Man.-Förster (1911) regarded the decrease of tone that follows deafferentation as so striking that he advocated this operation as a therapy for spastic limbs. After the operation he found

"it was possible to move the limbs passively, contraction (if not due to fibrosis) eventually disappeared, and flexor reflexes became less marked, no longer irradiating beyond the limb stimulated; in some cases they were completely stopped."

Pollock and Davis (1930) reported the deafferentation of an upper limb in a patient suffering from Parkinsonism. Unfortunately their account of the results does not provide a clear picture of the changes in tone and posture that ensued.

It may be concluded from this survey of reported work that chronically deafferented limbs are not devoid of tone; they may show a sustained posture. This is contrary to what is usually deduced from Sherrington's work on posture and tone. Although there is clearly a great diminution in normal tone, what tone remains has a particular distribution, and this seems to vary according to species. In the dog, although the deafferented limbs are almost flaccid immediately after the operation, one observer found that they developed strong abnormal extensor tone while another observer did not see this. In the cat marked extension and adduction have also been reported, but this does not occur in all animals. The deafferented forelimb of the monkey has been reported both as being flexed and adducted at the elbow, and also as hanging down and extended at the elbow; some of the posture in the monkey seems to depend on the activity of the neck reflexes. The hindlimb has been reported as being flexed at the hip and knee.

Effects of Cutting Posterior Roots on Respiratory Movements in the Cat.-A few experiments have been performed on the effects of posterior rhizotomy on the muscles used in respiration. These have all been acute experiments carried out on the anaesthetized or decerebrate cat. Coombs (1918) found that cutting the posterior thoracic roots caused "a diminution of costal respiration." In further experiments with Pike (1930), she found that in young kittens, from the time of birth till 10 days old, cutting the posterior thoracic roots almost stopped respiration; in older kittens this operation caused only a diminution in respiration. They described the following effects after cutting the posterior cervical roots in the kitten. "The movements of the diaphragm were much cut down and the respiratory rate was slowed. When the dorsal roots of both thoracic and cervical nerves are divided, kittens live only one to two hours and respiration is dyspnoeic." Similar experiments of dividing the posterior roots bilaterally were performed by Stella (1938). He found that cutting all the roots from the first cervical to the eleventh thoracic segments "did not seem to alter respiration, which was diaphragmatic before, and remained the same after the operation." Thus he found no effect on diaphragmatic movements. On the other hand, Sears (1958) when performing acute experiments on the Hering-Breuer reflexes in the cat, observed that after the cutting of posterior thoracic roots the activity of the intercostal muscles was reduced or abolished in the segment innervated by that root.

\section{New Observations on Man}

We now report the findings in three patients in whom certain posterior roots were cut. The deafferented muscles were of particular interest, $\stackrel{\odot}{\stackrel{\oplus}{\triangle}}$ for they included the diaphragm, an almost com-市 $\vec{\Omega}$ pletely automatic muscle, the intercostals, muscles used both in respiration and in posture, and the levator scapulae, a trunk muscle working in association with the upper limb. This choice of muscles permitted us to sample any alterations in activity in muscles of a mainly automatic type and in muscles used mainly in purposive directed movements.

Methods.-All three patients were examined before and after the operation of unilateral cutting of some cervical or thoracic roots. Sensibility was tested by the usual clinical methods, and the activity of muscles was assessed clinically. The movements of the diaphragm were examined radiologically by screening, with the patient standing. In two of the three patients electromyograms were also recorded from various muscles on both sides of the body with co-axial needle electrodes. The points at which the needles were inserted before the operation were tattooed so that after operation the needle could be inserted into the same region of the muscle. In one case photographs were taken of recordings made on a cathode ray oscillograph; in the other case records were also made of respiration, an ink-writing in which an oscillograph was used. To record respiration, the patient breathed through a wide-bored mouthpiece, his nose being clipped; one limb of a T-shaped tube was placed in the mouth, one limb was connected to a pressure recorder, and the third limb was left open to the air. Resistance to airflow could be increased by the addition of short lengths of rubber tubing to the open limb of the T-piece. Voluntary expiratory effort was tested by 
LEFT
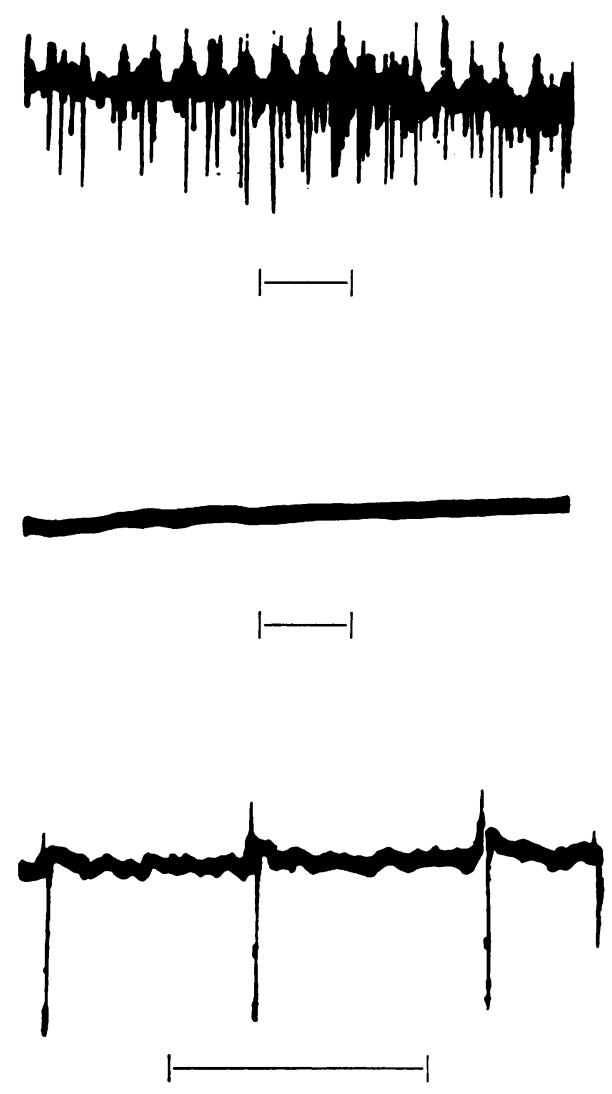

17

DAYS

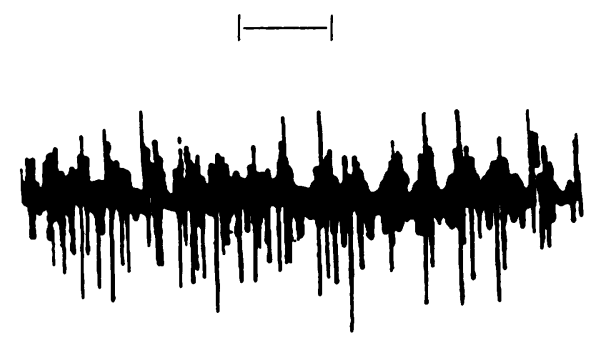

POST-OP.

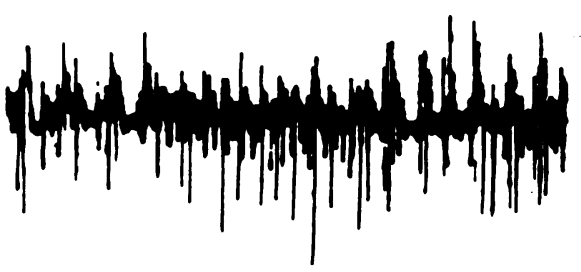

PRE-OP.

9 DAYS

POST-OP.

$1-1$

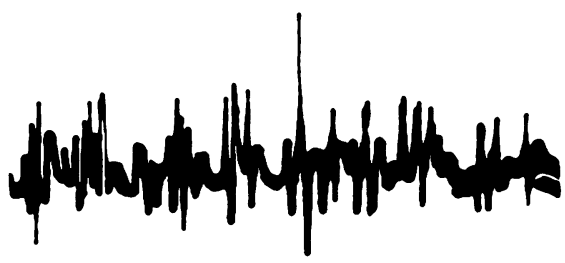

POST.OP.

Fig. 1.-Mr. H.B. Electromyograms of the levatores scapulae. The bracket beneath each record represents $100 \mathrm{~m}$.sec. The record nine days after operation shows no motor unit activity, and that 17 days after operation shows a single unit active during shrugging of the shoulders.

requiring the patient to hold up a column of water 10 to $50 \mathrm{~cm}$. high.

Results.-Mr. J. B. was suffering from carcinoma of the fauces which had spread to neighbouring lymphatic glands. For the relief of pain, Mr. Wylie McKissock divided the right ninth cranial nerve, and the right posterior roots of the first, second, third, and fourth and some fibres of the fifth cervical nerves.

Four days later the patient was well enough to be screened standing up. It was seen that the right half of the diaphragm was not moving. Three months later screening showed that both sides of the diaphragm moved, although the right half moved less well than the left; it showed no paradoxical movement.

Thus, division of the posterior roots of the cervical segments from which the phrenic nerve arises results in temporary paralysis of the diaphragm. Partial recovery occurs within three months. It was this observation that led us to investigate the activity of other muscles after deafferentation. Particular attention was paid to the levator scapulae, as this muscle has the same segmental innervation as the diaphragm.

Mr. H. B. was suffering from carcinoma of the left pyriform fossa, which caused him pain in the back of the head and on the left side of the neck. To relieve the pain, Mr. Alan Richardson divided the left posterior roots of the first, second, third, and fourth cervical nerves.

Six days after the operation, on screening, the left half of the diaphragm was seen to be paralysed; it was slightly elevated; during quiet respiration, it showed slight movements, in the normal directions; but when the patient was asked to take a deep breath or sniff, the left half of the diaphragm rose. On the ninth day this paradoxical movement was still present. Twelve days after the operation the action of the diaphragm was 
further examined while the patient breathed a mixture of $5 \% \mathrm{CO}_{2}$ and $95 \% \mathrm{O}_{2}$; the diaphragm moved asynchronously, the left side less than and after the right; both with this stimulant to breathing and on forced inspiration, what little movement of the left diaphragm occurred was paradoxical.

At this time the movements of the neck and the upper limbs were re-examined clinically and the muscles tested electromyographically. The patient tended to keep his head flexed, yet he could move his head as fully in all directions as he had done before the operation. The movements of both upper limbs were found to be normal; he could shrug his shoulders and lift his arms. But whereas before the operation the levator scapulae participated in this movement, as was seen clinically and shown electromyographically, after the operation no participation of the levator scapulae in the movements was seen nor was any found electromyographically; the right levator scapulae continued to function normally.

Sixteen days after operation the diaphragm was again examined radiologically: no paradoxical movement was seen and none could be induced; the movements, however, were delayed and of diminished excursion.

On the next day electromyographic examination of the left levator scapulae showed a few motor units in activity when the patient shrugged his shoulders, The electromyograms of the levatores scapulae before, nine and 17 days after posterior rhizotomy are shown in Fig. 1.

Thus, dividing the posterior cervical roots temporarily paralysed the diaphragm. This paralysis was recovering 16 days after the operation. Deafferentation of the levator scapulae also paralysed this muscle, and 17 days after the operation, there was also slight recovery from this paralysis.

Mr. H. M. was suffering from carcinoma of the bronchus, which had spread to involve the chest wall posteriorly, though it had not involved the intercostal nerves. For the pain of this condition, Mr. J. Brice divided the left posterior roots of the fourth, fifth, sixth, and some of the fibres of the seventh thoracic nerves. On the following day, inspection showed that the left side of the chest moved less than the right.

Electromyographic records were made before and after the operation from the fourth, fifth, and sixth intercostal muscles on both sides. These recordings were made with the patient sitting upright on a bench, with his back supported. The patient could not be reexamined electromyographically under these conditions till 14 days after operation.

In the electromyograms made before the operation, wherever the needle was inserted into the intercostal muscles, spontaneous activity was encountered. This consisted of two elements, units firing continually, and units firing in phase with respiration. Continual activity was nearly always encountered and was found to be influenced by posture. The amount of activity seen in phase with respiration depended on two factors: the position of the needle, and the type and depth of respiration. During quiet respiration, activity was usually slight, although some units could always be found firing with the respiratory rhythm. If the depth of the needle was increased a few millimetres often a different pattern would be found. As a general rule expiratory units were encountered deep in the intercostal space, inspiratory units being met with more superficially. All forms of activity were less on the left side of the chest than the right. An example of quiet respiratory activity, recorded before operation, is shown in Fig. 2a. When some resistance was placed in the airway, causing deeper breathing, fresh units were recruited, as shown in the lower record of Fig. 2a. The effects of breathing more deeply to command, of taking a very deep breath, and of supporting a column of water are shown in Fig. $2 b$. It will be seen that for each manoeuvre the activity was very much increased.

After the operation, the electromyograms on the unoperated right side were unchanged. On the left side, however, repeated sampling at various depths in the deafferented intercostal muscles showed less activity than pre-operatively, both in respiration and in the continual tonic activity, and less than could be found in the normally innervated spaces on the same side. It is to be noted that at the time of the examinations, the first of which was 14 days after operation, there was certainly not a complete absence of activity, as had been found earlier in the previous two cases. An example of the activity recorded on the fourteenth day from the fifth left intercostal space, a space in the centre of the deafferented region, is shown in Fig. 2c. Some units were found to be active during quiet respiration, and many more became active when the patient supported a column of water by expiratory effort. The activity in the deafferented intercostal muscles immediately after the operation in this patient is unknown. The evidence showed that 14 days or more after operation there was some activity in these muscles; this was less than that before operation and than that in the normally innervated intercostal muscles of both sides.

\section{Discussion}

The outstanding feature of the first two cases was that after cutting of the posterior cervical roots all movement of the corresponding muscles ceased. This paralysis was temporary; there was some recovery at the seventeenth day in one case; in both cases it was incomplete at the end of three months. The muscles tested were the diaphragm, a muscle the main function of which is respiratory, and the levator scapulae, a trunk muscle the activity of which is integrated with that of the upper limb. When these muscles are deafferented, testing during the first post-operative fortnight proved ineffective in inducing contraction: attempts to carry out movements to command, sudden sniffing, stimulation of respiration by chemical means, all failed to cause contraction of the muscles concerned. In the third case electromyographic evidence was not available during the first fortnight after posterior root section, though during this time it was seen that the left side of the chest moved less than before the operation. When electromyography again was 


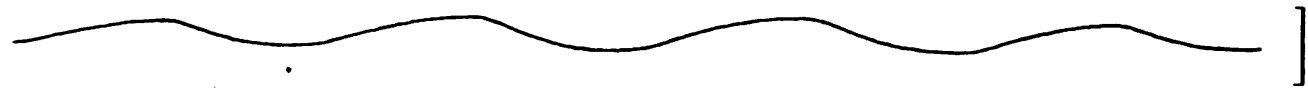

E.M.G.

Respiration

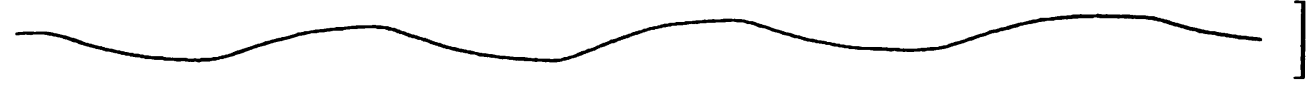

E.M.G.
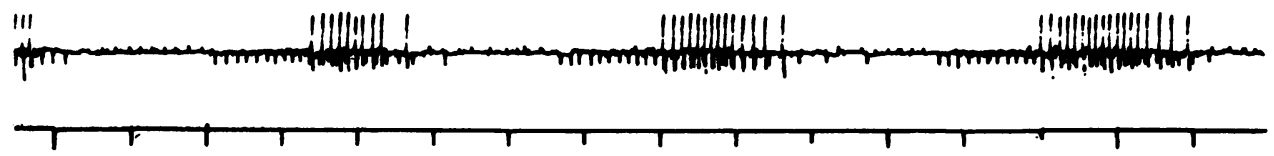

Fig. 2a.-Mr. H.M. Electromyograms recorded pre-operatively from the intercostal muscles of the fifth intercostal space. The time intervals are 1 second. The vertical bracket beside the respiratory record represents $5 \mathrm{~cm}$. of water at the junction of the T-piece; inspiration is shown by an upward deflection. The upper record made during quiet respiration shows a single unit firing intermittently on a background of continuous activity. The lower record shows the effect of adding resistance of less than $1 \mathrm{~cm}$. of water to the airway. Fresh units are recruited, and the unit previously active fires at a greater frequency and for a longer time.
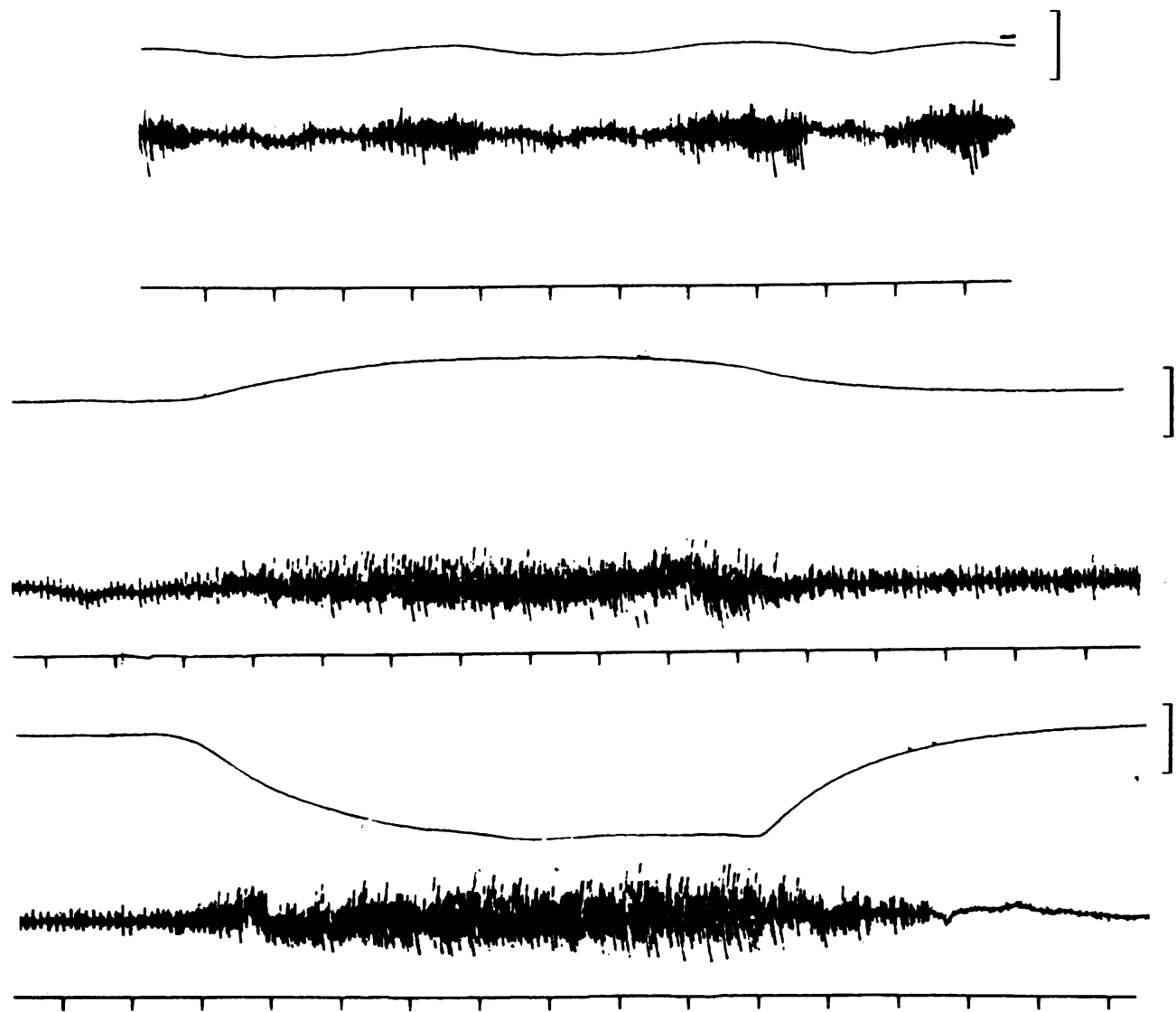

FIG. 2b.-Mr. H.M. Electromyograms recorded pre-operatively from the intercostal muscles of the fifth intercostal space. The vertical bracket on the right represents $20 \mathrm{~cm}$. of water. The upper record shows deeper breathing on command, the middle record is of taking a very deep breath, and the lower record was made while the patient supported a column of water by expiratory effort. 

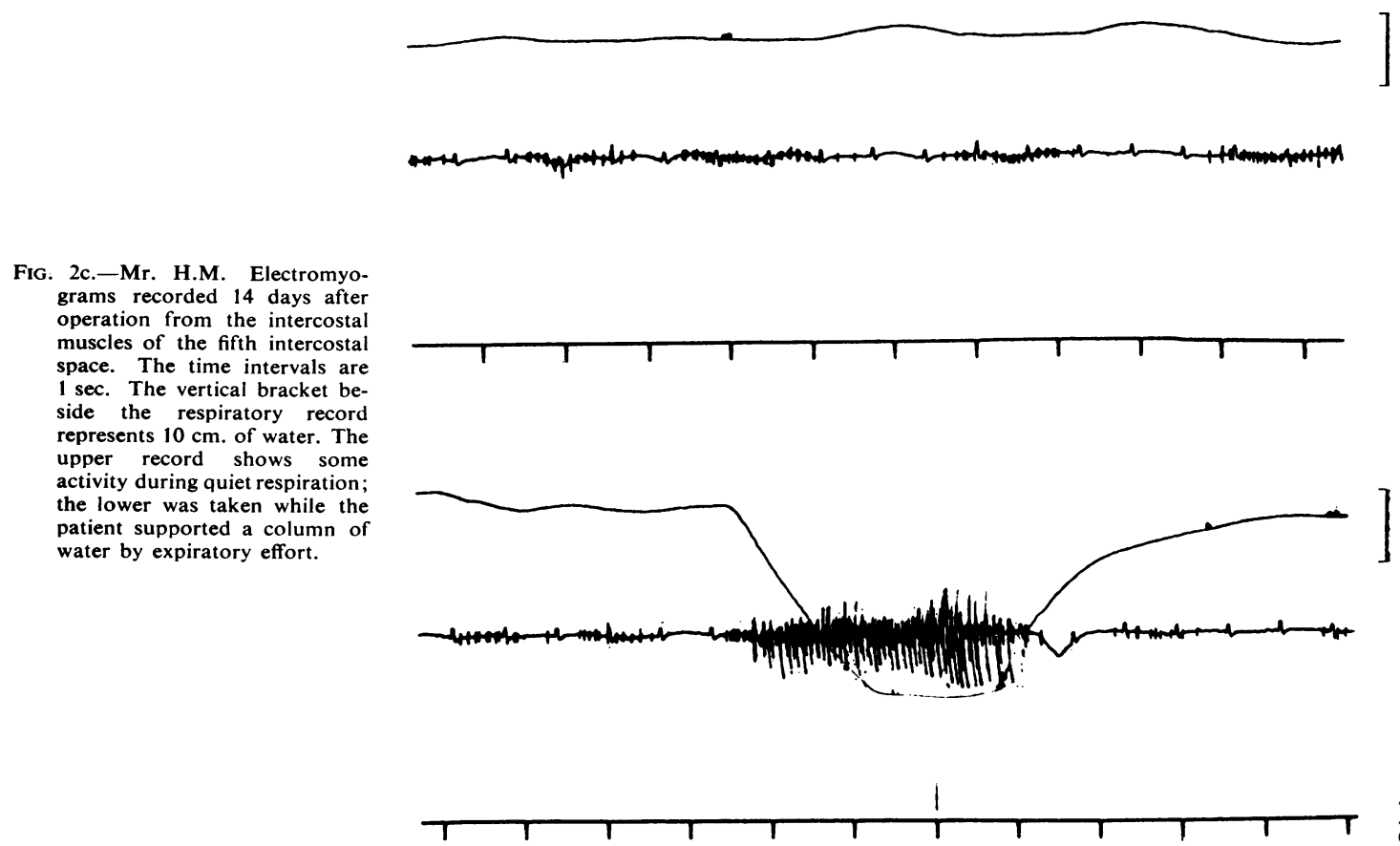

possible, the deafferented muscles were found to be active, though less so than before the operation and less than the neighbouring normally innervated muscles.

It could be suggested that the absence or diminution in electrical activity following the operation was due to inadequate sampling. As before the operation activity during muscular contraction was readily found at any needle position, we conclude that the absence of detectable activity electromyographically after operation may be taken as indicating a real inactivity of many motor units.

The paralysis of the diaphragm we observed is in direct contrast to the activity seen by Förster immediately after deafferentation of the upper limbs; and the electromyographic inactivity in the levator scapulae and later diminished activity in the intercostals also is in contrast to the excessive activity seen by Altenburger immediately after the operation.

The fact that posterior root section paralyses the corresponding respiratory muscles is of importance in learning about the normal control of respiratory muscles. The usual view of the activation of these muscles is that the motor neurones concerned are controlled by descending fibres having origin in the respiratory centres at supraspinal levels. It now appears from our present observations that the excitability of the spinal motor neurones used in respiration is also under the influence of the local segmental inflow; when this is suddenly cut off, impulses from supraspinal levels cannot activate the neurones innervating the diaphragm and, probably, the intercostal muscles.

As an explanation of the inactivity of muscles following deafferentation, we suggest that the likeliest hypothesis is that offered by Bastian (1895) that there is "a lowered functional activity in the motor centres situated in the spinal cord" following the removal of a usual afferent inflow. This general conception can be given greater precision nowadays, owing to the work on the different effects of cutting the posterior roots on the two routes of activation of muscles, the direct to the alpha motor neurones and the indirect via the gamma loop. Eldred, Granit, and Merton (1953) have shown that cutting the posterior roots stops all discharge of the corresponding motor neurones of alpha type in acute experiments on the Sherrington decerebrate cat. These and other similar observations led Granit (1955) to conclude that the alpha motor neurones are tonically facilitated by impulses from the muscle spindle afferents. We therefore suggest that the early paralysis that we observed is due to the sudden cutting off of the habitual afferent inflow to the alpha motor neurones.

This suggestion presupposes that the respiratory muscles are normally activated via the two routes known to exist for the limb muscles. There has so 
far been no investigation of the possible existence of a mechanism employing the direct and indirect routes for controlling the respiratory musculature. Indeed there is even disagreement on whether these muscles are equipped with muscle spindles. Dogiel (1903) has described and illustrated them in the intercostal muscles of the dog. Gregor (1904), who carried out an extensive study of spindles in the human foetus, found them present in the diaphragm, although, he wrote, this is one of the muscles where they are few. Fraenkel (1878), however, had failed to see them in the diaphragm; but he was examining atrophic muscles from patients who had died from phthisis. Batten (1897) also found none in the diaphragm, though he wrote that his examination of this muscle "had been by no means exhaustive". It seems then that one may conclude that the presence of spindles in the respiratory musculature is probable but not certain.

However, whether the muscles used in respiration are activated by the direct route or the indirect route, or as is more probable, a combination of the two, cutting the posterior roots results in the neurones of the final common path, the alpha motor neurones, ceasing to fire for some time.

The eventual recovery of the activity in the deafferented muscles of our cases must now be considered, for this is a phenomenon at least as important as the initial paralysis. Recovery was also seen in the limb muscles of monkeys, dogs, and cats by Hering, Bickel, von Korniloff, Munk, and Ranson.

Whether the route of activation of the muscles concerned is normally via the indirect or the direct route, or a combination of the two, recovery depends on the restoration of the excitability of the alpha motor neurones. An explanation might be that these neurones are exposed to an intensified bombardment of impulses from the remaining pre-synaptic fibres. Such an increase might result from an increased emotional need to use the paralysed muscles; but this explanation seems unlikely, for our patients had no increased motive to use the paralysed muscles, nor did they consciously try to re-learn to use them, being unaware of having any paralysis.

An increased bombardment of the respiratory motor neurones might be thought of as being due to an increase in the carbon dioxide tension, consequent on the paralysis of one-half of the diaphragm. However, this would have been maximal immediately after the operation, during the time of the paralysis. Moreover, increasing the carbon dioxide tension in the inspired air failed to make the paralysed diaphragm contract. It thus seems that recovery was dependent on some process other than an increase in the activity in existing pre-synaptic fibres.

A possible explanation is that in time the motor neurones themselves become more sensitive to the action of the chemical transmitters liberated at their pre-synaptic terminals as suggested by the work of Cannon and Haimovici (1939). They found that spinal neurones ipsilateral to a hemisection of the cord are more excitable than corresponding contralateral neurones. They concluded that the deprivation of the influence of the nerve fibres that normally connect to the neurones lowers their threshold to stimulation, and they considered that this phenomenon is one of sensitization following partial denervation.

Another explanation of recovery is that afferents from synergic muscles entering the cord via the intact adjacent posterior roots eventually become effective in restoring the excitability of the motor neurones. It is known from the work of Eccles, Eccles, and Lundberg (1957) that muscles having closely associated functions, such as synergists, share a common receptor field from which they draw monosynaptic excitation. It would not be far-fetched to consider the recovery as being due to an increased effectiveness of such connexions. In this manner the muscle spindles of synergic muscles could come to act as receptors for the motor neurones of the deafferented segment, thus re-establishing a gamma fibre loop.

The explanations given above depend on the increased effectiveness of transmission across existing synapses. An alternative mechanism could be that new synapses are laid down due to actual sprouting of collaterals and preterminals. Such sprouting has been described by Liu and Chambers (1958). They showed in the cat that it occurs throughout several segments caudal and cranial to a cut posterior root. Sprouting could cause the establishment of the correct connexions, for the sprouting occurs within the very region of the products of axonal degeneration. That such sprouting collaterals and preterminals can actually function has also been shown by McCouch, Austin, Liu, and Liu (1958). Such an explanation could provide a further way of accounting for the return of function to deafferented muscles in man.

\section{Summary}

An account is given of previous observations on the effects of cutting the posterior roots on the movements, posture, and tone of the limbs and of the respiratory musculature in cats, dogs, monkeys, and man.

Observations in man are reported on the effects of cutting posterior roots, especially on the activity of the respiratory muscles and a trunk muscle 
working in conjunction with the upper limb. After deafferentation these muscles ceased to contract; this paralysis was temporary. The possible explanations of the paralysis and return of function are discussed.

We would like to thank Dr. E. Arnold Carmichael and Dr. W. A. Cobb for the facilities they provided for doing this work, and the neurosurgeons mentioned who performed the operations.

\section{REFERENCES}

Altenburger, H. (1928). Arch. Psychiat. Nervenkr., 84, 501. 1937) In O. Bumke and O. Förster's Handbuch der Neurologie, Vol 3. Springer, Berlin.

Bastian, H. C. (1895). Proc. roy. Soc., 58, 89.

Batten, F. E. (1897). Brain, 20, 138.

Bell, C. (1811). Idea of a New Anatomy of the Brain. Privately printed.

Bickel, A. (1897). Pflüg, Arch, ges. Physiol., 67, 299. (1903). Untersuchungen über den Mechanismus der nervösen Bewegungsregulation. Enke. Stuttgart.

Cannon, W. B., and Haimovici, H. (1939). Amer. J. Physiol., 126, 731 Coombs, H. C. (1918). Ibid., 46, 459.

, and Pike, F. H. (1930). Ibid., 95, 681.
Dogiel, A. S. (1903). Arch. mikr. Anat., 62, 244.

Eccles, J. C., Eccles, R. M., and Lundberg, A. (1957). J. Physiol. (Lond.), 137, 22.

Eldred, E. Granit, R., and Merton, P.A. (1953). Ibid., 122, 498.

Förster, O. (1911). Disch. Z. Nervenheilk., 41, 146.

Forster, O. (1913). Surg. Gynec. Obstet., 16, 463.

(1936). In O. Bumke and O. Förster's Handbuch der Neurologie, Vol. 5. Springer, Berlin.

Fraenkel, E. (1878). Virchow's Arch. path. Anat., 73, 380.

Granit, R. (1955). Receptors and Sensory Perception. Yale Univ. Press, New Haven.

Gregor, A. (1904). Arch. Anat. Physiol., Lpz., Anat. Abt., p. 112.

Hering, H. E. (1897). Neurol. Zbl., 16, 1077

Korniloff, A. von (1898). Disch. Z. Nervenheilk., 12, 199.

Lassek, A. M. (1953a). Neurology, 3, 53.

- (1953b). J. Neuropath. exp. Neurol., 12, 83. (1955). Neurology, 5, 269.

- and Moyer, E. K. (1956). J. Neurophysiol., 16, 247.

Liu, C. N., and Chambers, W. W. (1958). A.M.A. Arch. Neurol. Psychiat., 79, 46.

McCouch G. $\ddot{\mathbf{P}}$ Austin, G. M. Liu, C. N., and Liu, C. Y. (1958). J. Neurophysiol., 21, 205.

Mott, F. W., and Sherrington, C. S. (1895). Proc. roy. Soc., 57, 481.

Munk, H. (1903, 1909). Uber die Funktionen von Hirn und Rückenmark. Hirschwald, Berlin.

Pollock, L. J., and Davis, L. (1930). Arch. Neurol. Psychiat. (Chicago). 23, 303 .

Ranson, S. W. (1928). Ibid., 19, 201

Sears, T. A. (1958). J. Physiol. (Lond.), 142, 35P

Sherrington, C. S. (1931). Brain, 54, 1 .

Stella, G. (1938). J. Physiol. (Lond.), 93, 10.

Twitchell, T. E. (1954). J. Neurophysiol., 17, 239. 